University of Wollongong

Research Online

Faculty of Law, Humanities and the Arts Papers (Archive)

Faculty of Arts, Social Sciences \& Humanities

$1-1-2019$

Developing Expertise: Benefits of Generalising Learning from the Graphic Design Project

Grant N. Ellmers

University of Wollongong, grante@uow.edu.au

Marius Foley

marius.foley@rmit.edu.au

Follow this and additional works at: https://ro.uow.edu.au/lhapapers

Part of the Arts and Humanities Commons, and the Law Commons

Research Online is the open access institutional repository for the University of Wollongong. For further information contact the UOW Library: research-pubs@uow.edu.au 


\title{
Developing Expertise: Benefits of Generalising Learning from the Graphic Design Project
}

\author{
Abstract \\ 2019 NSEAD and John Wiley \& Sons Ltd The ability to transfer knowledge between design projects has \\ been linked to developing expertise and, as such, is an important skill for designers. However, \\ externalising and analysing the knowledge from the design project in ways that support transfer can be a \\ challenge. This article explores how reflective practice can foster the conditions for knowledge transfer \\ and links these outcomes with design expertise characteristics. A structured and critical approach to \\ reflection was introduced alongside a graphic design project with the aim to foster the conditions for \\ transfer to other projects. A case study strategy of inquiry was employed, drawing on a qualitative \\ research approach, and framed by theories of reflective practice and cognitive psychology. The research \\ demonstrates that graphic design students readily reach an ability to describe, analyse and make \\ judgements from their design experience. However, the types of reflection that supports knowledge \\ transfer from one design experience to another - generalisation and abstraction - are not as apparent. \\ This outcome aligns with the behaviours associated with the expertise characteristics of a novice \\ designer.

\section{Disciplines} \\ Arts and Humanities | Law

\section{Publication Details} \\ Ellmers, G. \& Foley, M. "Developing Expertise: Benefits of Generalising Learning from the Graphic Design \\ Project." International Journal of Art and Design Education (2019):
}




\title{
Developing expertise: benefits of generalising learning from the graphic design project
}

\section{Grant Ellmers and Marius Foley}

\begin{abstract}
:
The ability to transfer knowledge between design projects has been linked to developing expertise and as such, is an important skill for designers. However, externalising and analysing the knowledge from the design project in ways that support transfer can be a challenge. This paper explores how reflective practice can foster the conditions for knowledge transfer and links these outcomes with design expertise characteristics. A structured and critical approach to reflection was introduced alongside a graphic design project with the aim to foster the conditions for transfer to other projects. A case study strategy of inquiry was employed, drawing on a qualitative research approach, and framed by theories of reflective practice and cognitive psychology. The research demonstrates that graphic design students readily reach an ability to describe, analyse, and make judgments from their design experience. However, the types of reflection that supports knowledge transfer from one design experience to another - generalisation and abstraction - are not as apparent. This outcome aligns with the behaviours associated with the expertise characteristics of a novice designer.
\end{abstract}

\section{Keywords:}

Knowledge transfer, design expertise, reflective practice, design process, novice designer 


\section{INTRODUCTION}

To improve levels of design expertise it is important designers transfer their knowledge between projects. A challenge, however, is to externalise and analyse the knowledge gained through the design project in ways that support transfer. Design knowledge typically exists in tacit forms, and for many designers this knowledge is only revealed through the activity of designing (Cross 2007; Schön 1992). Schon states "designers know more than they can say ... and they can best (or only) gain access to their knowledge in action by putting themselves into the mode of doing" $(1992$, p.3). It has been shown that if designers can shift their knowledge from tacit to explicit forms, this can foster the conditions for transfer (Ellmers 2014: 2015), where knowledge transfer is recognised as evidence of preparation for future learning (Bransford and Schwartz 1999). Bransford \& Schwartz (1999) further contend that analysing the project expereince in this manner can support the development of expertise.

The complexities relating to design knowledge and knowledge transfer specifically in a graphic design context have been highlighted (Ashton 2007; Ashton \& Isla 2003). Ashton states "the issue that lies at the heart of problems associated with the transfer of design knowledge is that it is situated and transforms as it transfers" $(2007$, p.1). She maintains that design knowledge can include materials and technology, processes and explicit information, and includes a tacit component which encompasses experience, values and intuition. Ashton reiterates the importance of the action/reflection learning approaches of designers, and the central role the artefact plays as a representation of knowledge, and in the communication and transfer of that knowledge.

In other design disciplines the ability to transfer knowledge has been identified as an important aspect of design practice. In an engineering design context, the processes associated with knowledge transfer has been shown to provide a means of engaging with the complexity of design problems, to draw on past experiences with the aim to inform development of design solutions, and to develop expertise (Busby 1988; 1999). Lauche identifies reflection as a method to support the improvement of design strategies and help practitioners to articulate assumptions and the intuitive knowledge inherent in their design 
process (2001). Wong et al (2016) in an industrial design context identified knowledge transfer as an important aspect of practice to assist the designer transition from novice to expert.

The phenomenon of knowledge transfer has been of interest in educational psychology for many years (Bransford \& Schwartz 1999; Girk \& Holyoak 1983; Hager \& Hodkinson 2009; Perkins \& Salomon 1988). Bransford and Schwartz (1999), recognising that transfer is a contentious topic, argue for a definition of transfer that includes evidence of what they identify as 'preparation for future learning'. That is, the ability to draw observations from the learning experience in a manner that supports transfer of learning to future experiences. They contend that the ability to learn from new experiences in this manner can place learners on a trajectory towards improving their levels of expertise (Bransford \& Schwartz 1999).

In the broader research literature reflective practice has been identified as a strategy that can provide direct support for transfer (Bransford \& Schwartz 1999; National Research Council 2000; Perkins \& Salomon 1988). Bransford and Schwartz (1999) suggest that people need help thinking about their experiences and organising them into some coherent view of the world. They state "an emphasis on metacognition, that is, helping students monitor, reflect upon, and improve their strategies for learning and problem-solving has shown to increase transfer" (1999, p.64).

The benefits reflection offers to learning from the design experience has been well documented in the design literature, for example, Valkenburg and Dorst (1998) Dorst (2003; 1995) Reymen et al. (2006), Lawson (2006) and Lauche (2001), with Schön's notion of the reflective practitioner $(1983 ; 1987)$ widely used as a conceptual basis. Reflection plays an important role in the design process as a means to explicitly engage with the thinking and understandings embedded in the activity of designing (Dorst \& Reymen 2004; Schön 1983).

Drawing generalisations from the design experience has also been identified as one way to support the development of design expertise (Lawson \& Dorst 2009). This has parallels with what Kokotovich and Dorst (2016) refer to as drawing general interpretations from the 
design experience in the form of 'abstractions', which they recognise as a key ability of expert designers.

The design expertise model described by Lawson and Dorst (2009) is a useful descriptor of design behaviours associated with different levels of expertise. They describe seven levels, with the levels novice (level 1) and expert (level 5) particularly informative for this study. Designers operating at a novice level will typically demonstrate behaviour where they "consider the objective features of a situation, as they are given by the experts, and will follow strict rules to deal with the problem" (Lawson \& Dorst 2009 p99). Lawson \& Dorst have observed that novice behaviour is typically evident where designers "have to think consciously about many elements of their technique leaving little time to concentrate on the target" (Lawson \& Dorst 2009, p84) Designers on the other hand demonstrating expert level behaviour will typically "respond to a specific situation intuitively, and perform the appropriate action straight away ... there is no problem solving and reasoning that can be distinguished at this level of working" (Lawson \& Dorst 2009). The capacity to abstract is seen as a key ability of expert designers and appears central to their ability to use their experience and knowledge to resolve a given problem (Kokotovich \& Dorst 2016). This would suggest that providing designers who demonstrate novice behaviours, with approaches that encourage the articulation of abstractions from the design experience, could support development of expertise.

It is important to note that these expertise levels are not a definitive single descriptor of a designer's competency, as they may display different levels of expertise behaviour across a single project (Lawson \& Dorst 2009). Making judgments about the importance of events and the weighing up of contributory factors is an indicator of transitions through levels of expertise (McDonnell et al. 2004). One element identified as central to the development of design expertise is reflective practice (Lawson \& Dorst 2009).

Drawing observations from the design experience in forms that can be applied to other projects and consideration of the broader context of design practice has been shown to support transfer (Ellmers 2014). This approach is described as as fostering the conditions for transfer (Ellmers 2014; 2015; 2017). In this study this was achieved through introduction of 
a structured and critical approach to reflective practice. Structured reflection is described as the process of "systematic reflection that is performed in a regular way during a design process" (Reymen, Hammer, Kroes, van Aken, Dorst, Bax \& Basten 2006 p. 148). Critical reflection is defined as reflection that "necessitates a change to deep-seated, and often unconscious, beliefs and leads to new belief structures" (Kember, McKay, Sinclair \& Wong 2008 p. 2). This paper reviews these findings, specifically concerning the concepts of generalisation and abstraction (described in Table 4), and relates these outcomes to the novice and expert behaviours described in the design expertise levels by Lawson \& Dorst (2009).

\section{METHODOLOGY}

A case-study approach (Yin 2003) was employed, supported by a qualitative research method (Creswell 2007). An intervention, drawing on the principles of structured and critical reflective practice, was designed and introduced to the participant cohort in the form of reflective assessment tasks. A cognition taxonomy was employed to identify levels of cognition evident in the participant reflective tasks and NVivo was used to code this data. The methodology is described below, and a more detailed account is presented in Ellmers (2014).

This study was conducted with students enrolled in a graphic design studio subject in the final session/semester of the three-year Bachelor of Creative Arts (Graphic Design) at the University of Wollongong, Australia. In this subject, students develop a major design work intended to serve as a signature work in their graduating design portfolio. Thirty-four students were enrolled in the subject. The participant cohort consisted of an equal gender split, with approximately $75 \%$ of the cohort aged $18-22,20 \%$ aged $23-30$, and $3 \% 30$ years and above. Approximately $70 \%$ of the cohort entered the program directly from school having completed the New South Wales Higher School Certificate, 17\% with no Higher School Certificate, and the remaining $13 \%$ with a range of qualifications from vocational institutions. This study obtained ethics approval from the University of Wollongong Human Research Ethics Committee. 


\subsection{The intervention}

An intervention was designed with the aim to support participants reflect on their project in a structured and critical way and in a manner that fosters the conditions for transfer. The intervention, which has been identified as structured critical reflective practice (described above), included a 4-step reflective process that guided the development of written reflective assessment tasks that where introduced to the participants. These stages and the theory that informed their design are outlined below, with greater detail available in Ellmers (2014).

\subsubsection{4-step reflective process}

The 4-step reflective process (summarised in Table 1) draws on the principles of reflectionon-action (Reymen 2003; Schön 1983), critical situations (Reymen et al. 2006), and critical incident analysis (Ghaye \& Lillyman 1997; Tripp 1993). Reflection-on-action has been defined as the thinking about the design activity after the activity, in such a way as to influence further activity (Reymen et al. 2006). Reymen et al. suggest that an important aspect of reflection-on-action is to identify and analyse critical situations from the design process, which they define as "situations that have an important influence on the further direction of the design process or the product being designed" (Reymen et al. 2006, p 169). Critical situations have parallels with what Tripp (1993), and Ghaye and Lillyman (1997) describe as critical incidents. It has been recognised that the process of identifying critical incidents requires an interpretation of the significance of an event (Tripp 1993). Subsequent analysis of the event's significance has been shown to help the practitioner develop their practice further and increase their level of expertise (Ghaye \& Lillyman 1997).

Table 1: 4-step reflective process

\begin{tabular}{|l|l|}
\hline Step 1 & $\begin{array}{l}\text { Initiate a reflective thinking process by pausing and standing back from the design } \\
\text { activity and review their design process }\end{array}$ \\
\hline Step 2 & $\begin{array}{l}\text { Critically reflect on their project by identifying and evaluating critical incidents from } \\
\text { their process }\end{array}$ \\
\hline Step 3 & $\begin{array}{l}\text { Connect thinking about the project with thinking about further development of their } \\
\text { project }\end{array}$ \\
\hline Step 4 & $\begin{array}{l}\text { Connect thinking about the project with thinking about possible approaches to other } \\
\text { projects in the future and/or their design practice }\end{array}$ \\
\hline
\end{tabular}


Step 1 of the 4-step reflective process aimed to initiate the process of reflective thinking by prompting the participants to pause and stand back from the design activity, through the activity of summarising their design process. This is important as the activity of designing often results in the designer being so immersed in the activity, they are not always in a position to stand back and consider their process critically and rationally (Dorst 1997).

Step 2 builds on step 1 and aims to promote critical reflection by prompting learners to review their design process (by referring to the material from step 1), identify critical incidents in their process, and then explain their rationale. This approach has been informed by the principles of critical incident analysis (Ghaye \& Lillyman 1997; Tripp 1993). Identifying critical incidents from the design process requires an interpretation of the significance of an event (Tripp 1993), and subsequent analysis of the event can help the practitioner develop their practice further and increase their level of expertise (Ghaye \& Lillyman 1997). Identifying and analysing critical situations from the design process can have an important influence on further development of the design project (Reymen et al. 2006).

Both steps 3 and 4 were designed to establish the conditions for transfer, where the participant draws observations from their current project in a manner that can be applied to projects in the future, or addresses the broader context of their design practice. This form of transfer has been referred to as 'preparation for future learning' (Bransford \& Schwartz 1999). Step 3 builds on steps 1 and 2 and was designed to prompt the learner to connect thinking about their project with thinking about subsequent development of their project. Step 4 prompts participants to extend their thinking further, and in light of their observations from steps 1-3, consider how they might now approach other design projects, or their design practice in general.

\subsubsection{Reflective learning tasks}

A series of written reflective assessment tasks were introduced to the participants at different stages during and after the development of their design artefact. The tasks consisted of a sequence of inter-related learning prompts that were designed to guide 
engagement by the participants with the 4-step reflective process described in Table 1. Learning prompts were defined as questions or hints that aim to encourage reflections about aspects of the project in specific ways. Learning prompts can assist engagement at a metacognition level, to promote a shift beyond the application of knowledge, to gain an understanding of that knowledge (Schraw 1998). Two forms of the reflective tasks were developed, a minor task and a concluding task.

The minor reflective assessment task guided the participants reflections during the development of the project and was applied at three key points in the project development. This occurred at the conclusion of the design proposal presentation, the design prototyping presentation; and the presentation of the final design artefact. The aim was to guide the participants to link reflections about their project with reflections about subsequent development of their project, and reflections about how they might approach other projects in the future in light of their experience. The task also served to guide participants to document their design process and reflections during the project for reference when completing the concluding reflective assessment task. The learning prompts and how they align to the 4-step reflective process are provided in Table 2 and are further detailed in Ellmers (2014).

Table 2: Minor reflective assessment task learning prompts

\begin{tabular}{|l|l|l|}
\hline \multicolumn{2}{|l|}{ Learning prompt (LP) } & $\begin{array}{l}\text { 4-Step reflective } \\
\text { process }\end{array}$ \\
\hline LP1 & $\begin{array}{l}\text { Briefly outline your design concept. } \\
\text { Summarise your design process. } \\
\text { Summarise the feedback you received from your design presentation. }\end{array}$ & Step 1 \\
\hline LP2 & $\begin{array}{l}\text { How do you feel about the feedback you received from your } \\
\text { presentation? } \\
\text { How do you feel about the progress of your design project to this point? }\end{array}$ & Step 1 \\
\hline LP3 & $\begin{array}{l}\text { Identify three significant aspects (critical incidents) of your design } \\
\text { process to date. Describe these critical incidents and explain why you } \\
\text { think these aspects are significant. }\end{array}$ & Step 2 \\
\hline
\end{tabular}




\begin{tabular}{|l|l|l|}
\hline LP4 & $\begin{array}{l}\text { How might the issues identified through the reflective process (from } \\
\text { Parts } 1 \text { and 2) help you further develop and refine your design project? } \\
\text { Why do you think this? }\end{array}$ & Step 3 \\
\hline LP5 & Do these issues remind you of any previous experience? If so how? & Step 3 or 4 \\
\hline LP6 & $\begin{array}{l}\text { In light of these issues, are there aspects of your design } \\
\text { technique/process you would approach differently in the future? If so } \\
\text { how? }\end{array}$ & Step 4 \\
\hline
\end{tabular}

The concluding reflective assessment task directed the participants to reflect back over the whole project once the artefact had been submitted for final assessment and included reviewing their responses to the three minor tasks. The concluding reflective assessment task was designed to prompt the participant to reflect in a structured manner over their whole project, and to promote connections between reflections about outcomes from their design project with reflecting about possible approaches to design projects in the future and/or the broader context of their design practice. This assessment task employed some similar learning prompts (LPs) to the minor tasks, but also included a further series of LPs specifically designed to encourage the participants to consider their whole project. The participants were asked to complete the concluding task after submission of the design artefact and completion of the minor tasks. The learning prompts and how they align to the 4-step reflective process are provided in Table 3 and further detailed in Ellmers (2014).

Table 3: Concluding reflective assessment task learning prompts

\begin{tabular}{|l|l|l|}
\hline \multicolumn{2}{|l|}{ Learning prompt (LP) } & $\begin{array}{l}\text { 4-Step reflective } \\
\text { process }\end{array}$ \\
\hline LP1 & $\begin{array}{l}\text { Briefly outline your design concept } \\
\text { Outline three primary references including their relevance. Describe } \\
\text { your design process that lead to the completion of your major design } \\
\text { project. }\end{array}$ & Step 1 \\
\hline LP2 & $\begin{array}{l}\text { Identify and describe } 3 \text { outcomes of your design project. Discuss why } \\
\text { you believe these outcomes are particularly significant. }\end{array}$ & Step 2 \\
\hline LP3 & $\begin{array}{l}\text { Compare your concept statement from the first reflective task with your } \\
\text { final statement. How has your concept changed? }\end{array}$ & Step 2 \\
\hline
\end{tabular}




\begin{tabular}{|c|c|c|}
\hline LP4 & $\begin{array}{l}\text { Do you feel your final concept statement is an improvement on the first? } \\
\text { Why? }\end{array}$ & Steps $1 / 2$ \\
\hline LP5 & $\begin{array}{l}\text { Look back over your responses to the three reflective tasks. What } \\
\text { patterns do you see emerging? }\end{array}$ & Step 2 \\
\hline LP6 & Identify and describe three things you have learnt during this project. & Step 2 \\
\hline LP7 & How might you apply this learning to future design situations? & Step 4 \\
\hline LP8 & $\begin{array}{l}\text { Now you have completed your project, do you see any alternative } \\
\text { outcomes? Why? }\end{array}$ & Step 4 \\
\hline LP9 & $\begin{array}{l}\text { Is there anything you would do differently in the future when } \\
\text { approaching a similar design situation? Why? }\end{array}$ & Step 4 \\
\hline LP10 & $\begin{array}{l}\text { How might the final outcomes from your design project prepare you for } \\
\text { industry or post-graduate study? } \\
\text { How might your reflections/observations from the reflective tasks } \\
\text { prepare you for industry or post-graduate study? }\end{array}$ & Step 4 \\
\hline
\end{tabular}

\subsection{Coding the participant reflective statements}

To code the reflective statements submitted by the participants, a cognition taxonomy was employed to identify the levels of cognition evident in the tasks. This taxonomy was developed based on the work of Bennett (2002), and Hatton and Smith (1995). In collaboration with Bennett, these cognition levels and their descriptors have been modified to allow application to this study and are described in Table 4.

For this study the computer software program QSR NVivo was employed to code the participant artefacts. This approach allowed subsequent matrix searches of the coded data to manage, shape, and support analysis. The participants reflective statements were coded at a sentence level, representing 'units of meaning' (Herrington \& Oliver 1999, p. 11) with each sentence aligned to one of the six cognition levels. When considering to what cognition level the sentence should be coded, the sentence context was taken into account, and if there was any coding doubt, the sentence was aligned to the lower cognition level. 


\begin{tabular}{|l|l|}
\hline \multicolumn{2}{|l|}{ Table 4: Cognition taxonomy } \\
\hline Cognition levels & Cognitive Descriptors \\
\hline $\begin{array}{l}\text { Reproductive } \\
\text { description }\end{array}$ & $\begin{array}{l}\text { Descriptive response that reproduces information directly from the case } \\
\text { with no elaboration }\end{array}$ \\
\hline $\begin{array}{l}\text { Summarising } \\
\text { description }\end{array}$ & $\begin{array}{l}\text { Descriptive response that summarises or synthesises or recounts } \\
\text { information presented in the project. }\end{array}$ \\
\hline Interpretation & $\begin{array}{l}\text { Seeks to explain or make sense of an event or statement by interpreting } \\
\text { information from the project. }\end{array}$ \\
\hline Judgement & $\begin{array}{l}\text { Goes beyond re-presenting or interpreting information to offer a value } \\
\text { judgement or claim }\end{array}$ \\
\hline Generalisation & $\begin{array}{l}\text { Presents a general observation or draws a generalising conclusion within the } \\
\text { context of the project }\end{array}$ \\
\hline Abstraction & $\begin{array}{l}\text { Presents a general principle or procedure that moves beyond the project } \\
\text { context to address a different or wider design context. }\end{array}$ \\
\hline
\end{tabular}

\section{RESULTS AND DISCUSSION}

The results are reported in two forms. In the first instance the data from all the reflective tasks are reported as one set with the aim to provide an overall picture of the levels of cognition evident by participants across the study. The data reported here was collected from 102 reflective reports, that is, 3 reports from each of the 34 participants. The data from first reflective assessment task has not been reported as it was deployed in a training role, with the aim to familiarise the participants with the introduced reflective practice. This approach addressed the possibility that some participants might perform poorly or inconsistently due to a lack of understanding of the report requirements. The second data set reports the results from the learning prompts (LPs) that were designed to specifically promote transfer. The aim is to provide a more detailed picture relating to what levels of cognition were evident when participants engaged with these LPs.

\subsection{Levels of cognition evident in participant reflective assessment tasks}

The combined results from the $2^{\text {nd }}$ and $3^{\text {rd }}$ minor reflective assessment tasks and the final concluding reflective assessment task are presented in Figure 1. 


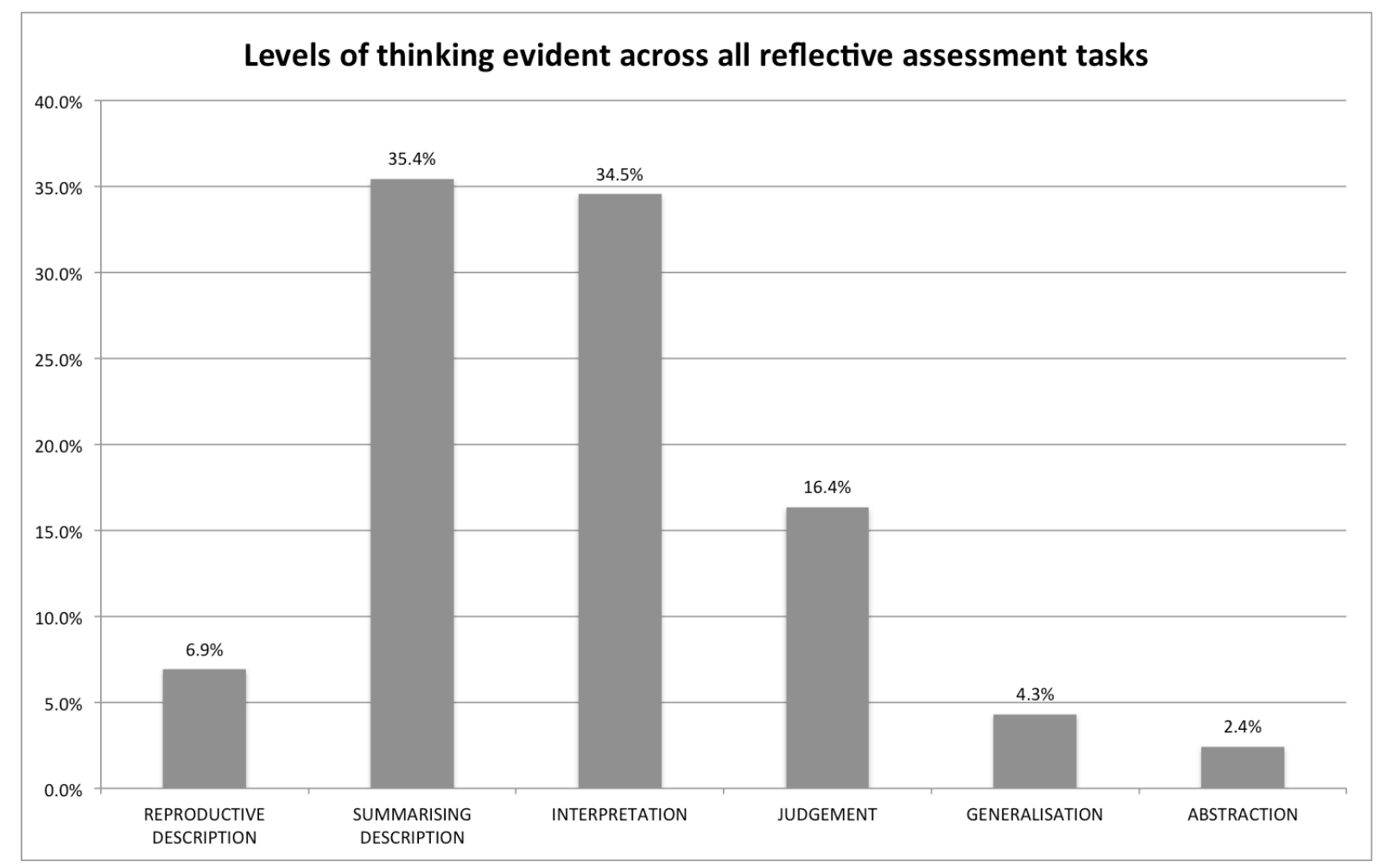

Figure 1: Data representing levels of cognition across all reflective assessment tasks

Reviewing the data from all reflective assessment tasks across the whole participant cohort reveals a pattern of the participants reflections. A significant component of the reflections $(42 \%)$ related to describing their design process (cognition levels Reproductive and Summarising Description). The majority of these reflections aligned with the cognition level Summarising Description (35\%) where participants made descriptive responses that summarised, synthesised, or recounted information from their design project. This outcome suggests that when prompted, learners can pause, stand back from their project, and describe their design process.

Half of the participants' reflections (52\%) represented analysis of their process (cognition levels Interpretation and Judgement). Of these reflections, the majority (34\%) occurred in ways that aligned with the cognition level Interpretation. This was typically represented when participants reviewed their design process and identified what they considered to be critical situations in their process. However, the results reveal fewer instances of the cognition level Judgement (16\%). Judgement was evident when participants sought to explain or make sense of an event or critical situation by moving beyond interpreting information to offering a value judgement or claim. This outcome was evident for example 
when a participant recognised that the introduction of a specific graphic element had been influential to the development of the project (Interpretation) and then explained their reasoning (Judgement), or recognised a shift in their approach (Interpretation) and then explained why they felt the shift was significant (Judgement). The results suggest that when prompted learners can identify critical situations from their design process, however there is likely to be fewer instances of value judgements or claims about the significance of the critical situations.

The results further reveal that when participants were asked to reflect on their project, there were significantly less instances of reflections that aligned with the cognition levels Generalisation (4\%) and Abstraction (2\%), that is, reflecting beyond the design process. Thinking that aligned with Generalisation was typically present when participants went beyond Interpretation and Judgement to present a general observation or make a generalising conclusion from the project within the same context as the project. Those observations that addressed a broader context than the project aligned with the cognition level Abstraction. These results reveal that despite prompting, there are likely to be fewer instances of generalised principles being articulated from the project.

This outcome demonstrates that $94 \%$ of the participants' reflections directly related to the design process, that is, the reflections was predominately embedded within the project. A significantly smaller component of participants' reflections (6\%) related to drawing generalised principles from the design experience, that is, reflecting beyond the project experience. This indicates that in the case of the structured reflective practice introduced in this study, instances of higher order cognition levels are most likely to occur in small quantities.

\subsection{Drawing generalisations and abstractions from the design process}

The methodology employed in this study allows the unpacking of the data at a more detailed level. In this case down to the individual learning prompts (LPs). Through a closer examination of these results it is possible to gain a richer understanding of what occurred. 
As the primary focus of this paper is examining how a structured approach to reflective practice can support designers to reflect on their experience in ways that foster the conditions for transfer, it is possible to examine the results from the LPs that were specifically designed to prompt this form of reflection. That is, drawing generalisations and abstractions from the project experience. This included the LPs from the minor reflective tasks and the concluding reflective task that prompted participants to link reflections on the project with reflections about projects in the future and reflections on their approach to practice. While these LPs are provided in Table 2 and 3, they are repeated below in Table 5 as a reminder. The results are presented in Figure 2.

Table 5: Reflective assessment task learning prompts

\begin{tabular}{|c|c|c|c|}
\hline & Learning prompt (LP) & Aim of prompt & $\begin{array}{l}\text { Link to 4-Step } \\
\text { reflective process }\end{array}$ \\
\hline \multicolumn{4}{|c|}{ Minor reflective assessment task } \\
\hline LP6 & $\begin{array}{l}\text { In light of these issues, are there aspects } \\
\text { of your design process you would } \\
\text { approach differently in the future? If so } \\
\text { how? }\end{array}$ & $\begin{array}{l}\text { To link reflecting } \\
\text { about the project with } \\
\text { reflecting about } \\
\text { projects in the future }\end{array}$ & Step 4 \\
\hline \multicolumn{4}{|c|}{ Concluding reflective assessment task } \\
\hline LP9 & $\begin{array}{l}\text { Is there anything you would do } \\
\text { differently in the future when } \\
\text { approaching a similar design situation? } \\
\text { Why? }\end{array}$ & $\begin{array}{l}\text { Projecting new } \\
\text { knowledge to a similar } \\
\text { design context in the } \\
\text { future }\end{array}$ & Step 4 \\
\hline LP10 & $\begin{array}{l}\text { How might the final outcomes from your } \\
\text { design project prepare you for industry } \\
\text { or post-graduate study? } \\
\text { How might your reflections/observations } \\
\text { from the reflective tasks prepare you for } \\
\text { industry or post-graduate study? }\end{array}$ & $\begin{array}{l}\text { Projecting new } \\
\text { knowledge to the } \\
\text { wider context of } \\
\text { design practice }\end{array}$ & Step 4 \\
\hline
\end{tabular}

In Figure 2 the rows indicate the learning prompt (LP) number and the percentage of participants who responded to this learning prompt, while the columns represent the different cognition levels. For example, the results reveal that in the minor reflective task for LP6, $100 \%$ of participants responded to this learning prompt, with $71 \%$ of participants reflections on their project aligning with the cognition level Abstraction. 


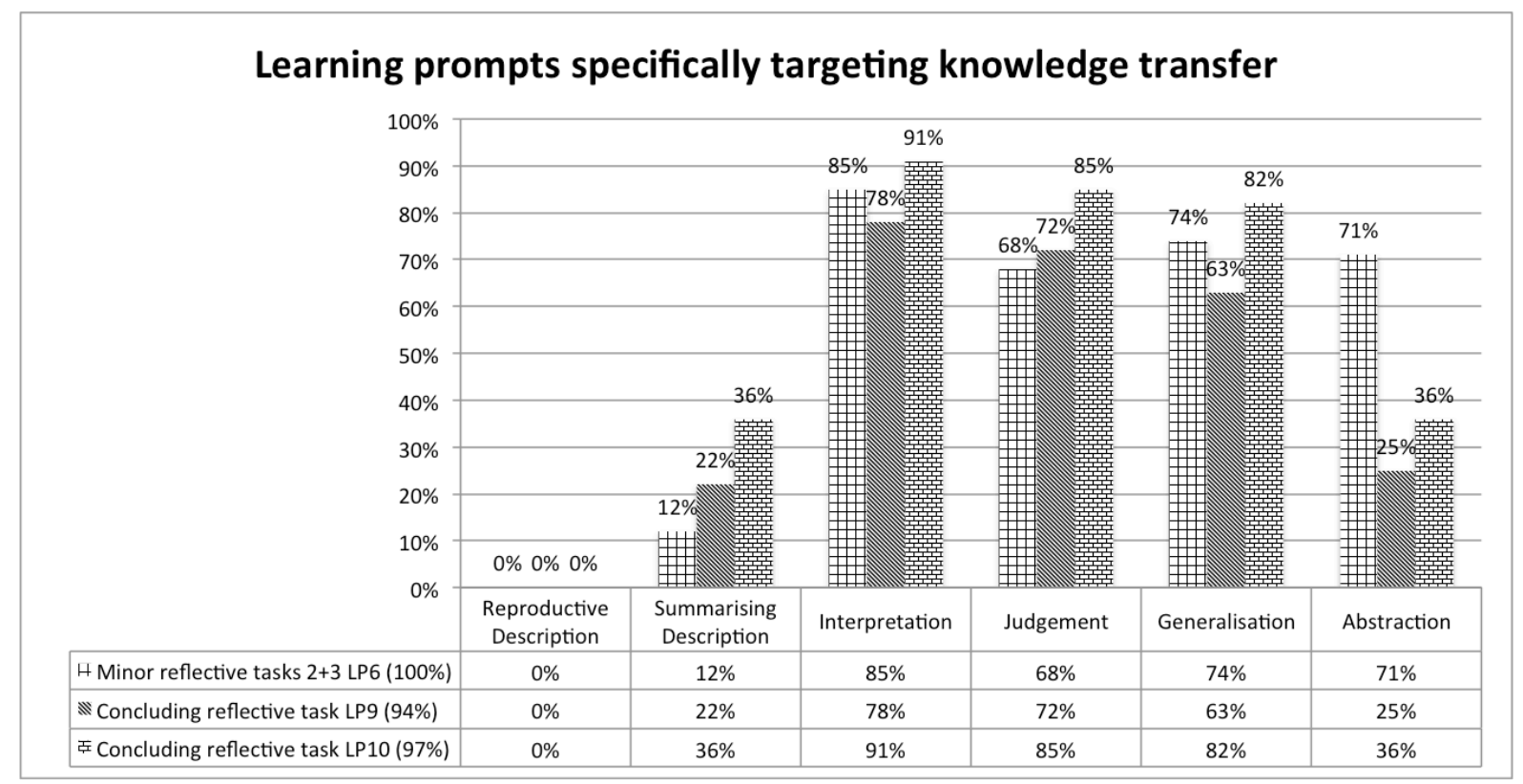

Figure 2: Results from learning prompts fostering the conditions for knowledge transfer

The results from the LPs specifically designed to prompt participants to draw general observations or conclusions from the design experience, reveal a more detailed picture than the generalised approach presented in Figure 1. All participants responded to LP6 from the minor reflective task, with $74 \%$ of participants linking their reflections on the project with reflecting about similar context projects in the future (Generalisation), and 71\% linking their reflections with a broader context than the project context (Abstraction).

Reviewing the concluding reflective task reveals a different picture. When asked specifically to draw generalising conclusions within the same context as the project (LP9) 63\% did so in a way that aligned with the cognition level Generalisation. When specifically asked to draw conclusions in a broader context than the project (LP10) only $36 \%$ achieved this level of cognition, that is, their reflections aligned with the cognition level Abstraction. Interestingly, in LP10, despite prompting participants to reflect outside of the project context, the reflections of $82 \%$ of participants aligned with Generalisation, that is, they reflected within the same context as the project, not beyond the project.

Across the whole study $79 \%$ of participants reflected on their project in ways that aligned with Generalisation and $70 \%$ with Abstraction (see Figure 1). This outcome is similar to the 
results from LP6 in the minor reflective task (74\% Generalisation and 71\% Abstraction). However, there was a marked difference in the results for Abstraction when examining the concluding reflective task. In LP9 only $25 \%$ of participants' reflections aligned with Abstraction and $36 \%$ in LP10. The outcome for LP9 is understandable as this LP was designed to specifically prompt thinking within the project context (Generalisation) not outside the project (Abstraction). However, for LP10 participants were specifically prompted to shift their reflections beyond the project context (Abstraction) yet only $36 \%$ of participants' reflections occurred in this manner. This behaviour has parallels with novice level expertise where designers are more likely to reflect on their project experience within the context of the project, and even with direct prompting, may not readily link reflecting about the project with reflecting beyond the project.

It is not possible from this data set to explain the discrepancy between the levels of Abstraction in the minor and the concluding reflective tasks. It could be argued this is a limitation of collecting one form of data with a small number of participants. However, in a secondary data set collected as part of a data triangulation strategy (reported in Ellmers 2014), some participants indicated they had difficulty finding the motivation to complete the concluding reflective task once the project artefact had been submitted. Post-project depression identified by Lawson and Dorst (2009) may be a factor, where psychologically the designer or design team are unlikely to be in the right frame of mind to reflect on the project once it has finished. They suggest "one possible way forward is to require teams to perform a review of recent relevant projects at the beginning of each new project" (Lawson \& Dorst 2009, p. 288). Linking the current project with past projects is also an approach suggested by McDonnell (2011). Potential exists for further research to better understand how graphic designers behave in this situation.

\subsection{Results and discussion summary}

The outcomes from this study indicate that reflection, introduced as a structured and critical practice, can support designers to reflect on their design process in ways that foster the conditions for transfer. This outcome was evident in four stages:

- participants engaged in a deliberate process of pausing to think back over the project by describing their process; 
- they explored the understandings that have been brought to the handling of the process by identifying critical situations and making value claims about the significance of the situation;

- they drew generalised principles from the project by considering how they might now approach further development of their project;

- they connected these reflections with reflecting beyond the project context by considering possible approaches to design projects in the future and or approaches to practice.

Not all participants however reflected on their design project in these ways, or achieved these forms of reflections all the time. While all participants identified what they considered to be critical situations from their process in a manner consistent with the cognition level Interpretation, fewer participants however made value judgements or claims about the significance of the critical situations (Judgement). The results further revealed that despite direct prompting, not all participants drew generalised principles from their reflections about the project. Those participants who did were more likely to reflect on their project within the same context as the project, with fewer participants shifting their reflections beyond the project context.

\section{CONCLUSIONS AND FURTHER RESEARCH}

The findings from this study link the process of drawing reflective observations from the design experience with concepts of knowledge transfer and design expertise. This study demonstrates that reflective practice performed in a structured and critical manner can support design students to identify and analyse the knowledge embedded in their process and draw generalised reflections in ways that foster the conditions for transfer. This occurred in ways that informed further development of their project, and supported reflecting about approaches to projects in the future and/or the broader context of design practice. However, the cognition levels required to foster the conditions for knowledge transfer from one design experience to another - generalisation and abstraction - where not as readily apparent in the reflections of the participants. This outcome has parallels with the behaviour characteristics at a novice expertise level as described by Lawson \& Dorst (2009). 
This study contributes to Kokotovich \& Dorst (2016) who identify the need for more research into the abstraction behaviour of novice and expert designers, and the creation of methods and tools to support designers achieve improved levels of design expertise. They identify abstraction as the process of drawing desituated concepts from the design experience. This has parallels with the concept described in this paper of drawing generalised and abstract observations from the design experience. Both concepts represent meta-level reflection on the design process and experience.

In this study the participant group were undergraduate design students and generally demonstrated novice level behaviours. The next stage in this research is to examine how graphic designers who demonstrate expert level behaviours, reflect about their experiences, and do they reflect in ways that foster the conditions for knowledge transfer. The concept of the design conversation described by Foley (2012) can provide an approach to frame engagement with designers in an industry setting.

\section{Author biographies}

Grant Ellmers is an academic in the School of the Arts, English and Media at the University of Wollongong. His research interests include the creative process, knowledge transfer, reflective practice, and design education including studio and project-based learning. Grant has published nationally and internationally. His PhD thesis is titled Graphic Design Education: Fostering the conditions for transfer in a project-based and studio-based learning environment, through a structured and critical approach to reflective practice. Grant teaches design thinking, design process, user interface design, research methodology, and photography. Contact: University of Wollongong, Faculty of Law, Humanities and the Arts, Northfield Ave, Wollongong, New South Wales, Australia 2522. Email: grante@uow.edu.au

Marius Foley is the Program Manager of the Master of Design Futures, RMIT School of Design. This Masters is the study and practice of human centred design in contemporary situations for design practitioners. In the program Marius directs the Mindful Design Leadership course, which is an investigation of new models of leadership, grounded in human centred approaches. Marius supervises students in the Design Futures Research Project as well as practice-based PhD design students. In his PhD, Co-Creative Publics and 
Publication Design, he examines the changing relationship of design to the publics it addresses. Marius' research areas include design education; design engagements with aged care and approaches to death; and design and media innovation, especially in rural and remote communities. Contact: RMIT University, School of Design, Melbourne, Victoria, Australia.Email: marius.foley@rmit.edu.au

\section{REFERENCES}

Ashton, P., 2007, Transferring and Transforming Design Knowledge. Experiential Knowledge Conference. Niedderer, K. \& Reilly, L. University of Hertfordshire, London Metropolitan University, UK.

Ashton, P. \& Isla, J. 2003, 'Transforming Design Consultancy Through Learning', Design Management Journal, Vol. 14, No. 3, pp. 72-77.

Bennett, S. 2002, Learning about design in context: An investigation of learners' interpretations and use of real-life cases within a constructivist learning environment created to support authentic design activities, $\mathrm{PhD}$ thesis, University of Wollongong, Wollongong.

Bransford, J. D. \& Schwartz, D. L. 1999, 'Rethinking transfer: A simple proposal with a multiple implications ', Review of Research in Education, Vol. 24, No., pp. 61-101.

Busby, J. S. 1988, 'Effective practices in design transfer', Research in Engineering Design, Vol. 10, No. 3, pp. 178-188.

Busby, J. S. 1999, 'The problem with design reuse: An investigation into outcomes and antecedents', Journal of Engineering Design, Vol. 10, No. 3, pp. 277-296.

Creswell, J. W. 2007, Qualitative inquiry and research design: Choosing amoung five approaches, Sage, Thousand Oaks, CA.

Cross, N. 2007, Designerly Ways of Knowing, Springer, London.

Dorst, K. 1997, Describing Design - A Comparison of Paradigms, Delft University Press, Delft, The Netherlands. 
Dorst, K. 2003, 'The Problem of Design Problems', in Expertise in Design, Design Thinking Research Symposium 6, University of Technology, Sydney, 17-19 November.

Dorst, K. \& Dijkhuis, J. 1995, 'Comparing paradigms for describing design activity', Design Studies, Vol. 16, No. 2, pp. 261.

Dorst, K. \& Reymen, I. M. M. J. 2004, 'Levels of expertise in design education', in 2nd International Engineering and Product Design Education Conference, Delft University of Technology, Delft, September 2-3.

Ellmers, G. 2014. Graphic Design Education: Fostering the conditions for transfer in a project-based and studio-based learning environment, through a structured and critical approach to reflective practice. Doctor of Philosophy, University of Wollongong, Wollongong.

Ellmers, G. 2015. The graphic design project: employing structured and critical reflection to guide student learning. Communication Design, 3, 62-79

Ellmers, G. 2017. Connecting learning from the graphic design project with thinking about approaches to design practice. Art, Design and Communication in Higher Education: Special issue Graphic Design Education, 16, 69-82.

Foley, M. 2012. Co-creative Publics and Publication Design Practice. Doctor of Philosophy RMIT University, Melbourne.

Ghaye, T. \& Lillyman, S. 1997, Learning journals and critical incidents: Reflective practice for health care professionals Quay, Dinton, England.

Girk, M. L. \& Holyoak, K. J. 1983, 'Schema induction and anological transfer', Cognitive Psychology, Vol. 15, No., pp. 1-38.

Hager, P. \& Hodkinson, P. 2009, 'Moving beyond the metaphor of transfer of learning', British Educational Research Journal, Vol. 35, No. 4, pp. 619-638.

Hatton, N. \& Smith, D. 1995, 'Reflection in teacher education: Towards definition and implementation', Teaching and Teacher Education, Vol. 11, No. 1, pp. 33-49.

Herrington, J. \& Oliver, R. 1999, 'Using Situated Learning and Multimedia to Investigate Higher-Order Thinking', Journal of Interactive Learning Research, Vol. 10, No. 1, pp. 3-24. 
Kokotovich, V.\& Dorst, K. 2016, 'The art of 'stepping back': Studying levels of abstraction in a diverse design team', Design Studies, Vol. 46, No., pp. 79-94.

Lauche, K. 2001, 'Heedful action, reflection, and transfer in the design process', in International conference on Engineering Design No13, Glasgow.

Lawson, B. 2006, How designers think: The design process demystified Architectural Press, Oxford, UK.

Lawson, B. \& Dorst, K. 2009, Design Expertise, Architectural Press, Oxford, UK.

McDonald, J. P. 2011, 'Impositions of order: A comparison between design and fine art practices', Design Studies, Vol. 32, No., pp.

McDonnell, J., Lloyd, P. \& Valkenburg, R. C. 2004, 'Developing design expertise through the construction of video stories', Design Studies, Vol. 25, No. 5, pp. 509-525.

National Research Council 2000, How people learn: Brain, mind, experience, and school, National Academy Press, Washington, DC.

Perkins, D. N. \& Salomon, G. 1988, 'Teaching for transfer', Educational Leadership, Vol. 46, No. 1, pp. 22-32.

Reymen, I. M. M. J. 2003, 'Research on Design Reflection: Overview and Directions', in 14th International Conference on Engineering Design (ICED03), Stockholm, Sweden, August 1921.

Reymen, I. M. M. J., Hammer, D. K., Kroes, P. A., van Aken, J. E., Dorst, C. H., Bax, M. F. T. \& Basten, T. 2006, 'A domain-independent descriptive design model and its application to structured reflection on design processes', Research in Engineering Design, Vol. 16, No. 4, pp. 147-173.

Schön, D. 1992, 'The Theory of Inquiry: Dewey's Legacy to Education', Curriculum Inquiry, Vol. 22, No. 2, pp. 119-139.

Schön, D. A. 1983, The Reflective Practitioner: How professionals think in action, Basic books, New York. 
Schön, D. A. 1987, Educating the Reflective Practitioner, Jossey-Bass Inc, San Francisco.

Schön, D. A. 1992, 'Designing as reflective conversation with the materials of a design situation', Knowledge-Based Systems, Vol. 5, No. 1, pp. 3-14.

Schraw, G. 1998, 'Promoting general metacognitive awareness', Instructional Science, Vol. 26, No., pp. 113-125.

Tripp, D. 1993, Critical incidents in teaching: Developing professional judgement, Routledge, London, UK.

Valkenburg, R. \& Dorst, K. 1998, 'The reflective practice of design teams', Design Studies, Vol. 19, No. 3, pp. 249-272.

Wong, J. J., Chen, P. Y. \& Chen, C. D. 2016, 'The Metamorphosis of Industrial Designers from Novices to Experts', International Journal of Art \& Design Education, Vol. 35, No. 1, pp. 140-153.

Yin, R. K. 2003, Case Study Research: Design and Methods Third Edition, Sage Publications, Thousand Oaks, CA. 